\title{
Bleeding risk in patients with venous thromboembolic events treated with new oral anticoagulants
}

\author{
Niklas Wallvik ${ }^{1} \cdot$ Henrik Renlund ${ }^{2} \cdot$ Anders Själander $^{1}$
}

Accepted: 21 October 2020 / Published online: 2 November 2020

(c) The Author(s) 2020

\begin{abstract}
New oral anticoagulants (NOACs) is the preferred treatment in secondary prophylaxis of venous thromboembolic events (VTE). The aim of this study was to investigate possible risk factors associated with major bleeding in VTE-patients treated with NOACs. In this retrospective register-based study we screened the Swedish anticoagulation register Auricula (during 2012.01.01-2017.12.31) to find patients and used other national registers for outcomes. Primary endpoint was major bleeding defined as bleeding leading to hospital care. Multivariate Cox-regression analysis was used to reveal risk factors. 18219 patients with NOAC due to VTE were included. 85.6\% had their first VTE, mean age was 69.4 years and median follow-up time was 183 days. The most common NOAC was rivaroxaban (54.8\%), followed by apixaban (42.0\%), dabigatran (3.2\%) and edoxaban (0.1\%). The rate of major bleeding was 6.62 (95\% CI 6.19-7.06) per 100 treatment years in all patients and 11.27 (CI 9.96-12.57) in patients above 80 years of age. Statistically independent risk factors associated with major bleeding were age (normalized HR 1.38, CI 1.27-1.50), earlier major bleeding (HR 1.58, Cl 1.09-2.30), COPD (HR 1.28, CI 1.04-1.60) and previous stroke (HR 1.28, Cl 1.03-1.58) or transient ischemic attack (TIA) (HR 1.33, Cl 1.01-1.76). Prior warfarin treatment was protective (HR 0.67 , CI $0.58-0.78$ ). This real world cohort shows a high bleeding rate especially among the elderly and in patients with previous major bleeding, COPD and previous stroke or TIA. This should be considered when deciding on treatment duration and NOAC dose in these patients.
\end{abstract}

Keywords New oral anticoagulants $\cdot$ Venous thromboembolism $\cdot$ Major bleeding $\cdot$ Risk factors

\section{Highlights}

- Register study to examine risk factors for major bleeding on NOAC-treatment due to VTE.

- High age, history of major bleeding, COPD and previous stroke or TIA increase the risk of major bleeding.

- Previous anticoagulation with warfarin confers lower bleeding risk.

Electronic supplementary material The online version of this article (https://doi.org/10.1007/s11239-020-02319-w) contains supplementary material, which is available to authorized users.

Niklas Wallvik

niklas.wallvik@gmail.com

1 Department of Public Health and Clinical Medicine, Umeå University, 98187 Umeå, Sweden

2 Uppsala Clinical Research Center, Uppsala University, Uppsala, Sweden
- The rate of major bleeding is especially high among elderly (11.27 per 100 treatment years).

\section{Introduction}

The incidence of first VTE in the general population is about $0.1 \%$ per year $[1,2]$. Total mortality associated with the diagnosis of acute pulmonary embolism is $8-17 \%$ in three months follow-up time and more than doubles after discharge from hospital [3]. In 1960, a medical breakthrough was made when vitamin K-antagonists (VKAs) was introduced as oral anticoagulant treatment of VTE [4]. A systematic review of patients with VTE on vitamin K antagonist treatment found a risk of recurrence of $3.5 \%$ ( $0.5 \%$ lethal) and a risk of major bleeding of $1.6-2.1 \%(0.2 \%$ lethal) during 3-6 months [5]. After 3 months, the risk of major bleeding is estimated to be $0.8 \%$ per patient year or 2,6 times more than without anticoagulant treatment [6]. A metaanalysis of available randomized controlled trials (RCTs) 
comparing NOACs with warfarin in treatment of acute VTE reported an equivalent efficacy but significantly lower risk of major bleeding, $1.1 \%$ vs $1.7 \%$ (RR $0.695 \%$ CI $0.4-0.9$ ) during mainly a treatment period of 6 months. Irrespective of treatment group, there was a negligible risk of lethal pulmonary embolism and no difference in mortality $(2.4 \%$ vs $2.4 \%$ ) [7]. Risk factors for major bleeding on low molecular weight heparin (LMH) and VKAs in patients with VTE are age $>65$, earlier bleeding, cancer, kidney failure, thrombocytopenia, low time in therapeutic range (TTR), surgery, alcoholic abuse and fall [6]. In a register study from a Swedish cohort, independent risk factors of major bleeding on VKA-treatment in VTE-patients were identified as age, cardiac failure, chronic obstructive pulmonary disease (COPD), alcoholic abuse, anemia, hypertension and a history of major bleeding [8]. Risk factors for major bleeding in patients on NOACs as well as warfarin has been extensively studied in atrial fibrillation, but not in patients with VTE. Anemia or history of major bleeding, age $>75$, vascular disease, abnormal renal function, abnormal liver function, excessive alcohol, antiplatelet agents or non-steroidal anti-inflammatory drugs are described as risk factors in patients with NOACs due to atrial fibrillation [9]. In addition, certain metabolically interactive substances seem to be of importance [10]. The bleeding risk with NOACs in atrial fibrillation has also been studied specifically in the elderly (mean age 81.6 ) and estimated to $4.4 \%$ for major bleeding and $5.7 \%$ for clinically relevant non-major bleeding at 12 month follow-up [11]. Risk factors for major bleeding in patients with NOAC treatment due to VTE might distinguish from atrial fibrillation. VTE-patients of course has another underlying disease, they are five-ten years younger and even though they share characteristics like occurrence of smoking and obesity they also diverse in comorbidities like presence of cancer $[1,12,13]$. The aim of this study was to investigate possible risk factors associated with major bleeding in VTE-patients treated with NOACs.

\section{Material and methods}

The study was approved by the ethical research committee in Umeå, Dnr 2015/145-31. Data were collected from the Swedish national quality register for oral anticoagulation (Auricula), the Swedish National Patient Register (NPR) and The Cause of Death Register (CDR). According to the latest published yearly report Auricula has over 150000 active patients, the coverage ratio is estimated to be about $50 \%$ with no apparent selection bias, NOAC represents about half of the treatment years and the VTE indication constitutes $18 \%$ of all patients with oral anticoagulation [14]. The NPR contains diagnoses defined as ICD-10 codes on hospital admissions and outpatient clinics for patients with a Swedish personal identity number. About $99 \%$ has a valid personal number and current absence of primary diagnosis at hospital admission or in outpatient clinics is only $0.9 \%$ and $3.2 \%$ respectively [15]. The $C D R$ consists of all identified deaths in Sweden with a personal identity number and information includes age, sex, date and cause of death.

In this study Auricula was used to find patients on treatment with NOAC due to a physician reported VTE between 2012.01.01 and 2017.12.31. Individual patients could only be included once, therefore, in patients registered several times, only the first treatment period was included. Using personal identity number included patients where then identified in the NPR and the $C D R$ to find characteristics at baseline and endpoints (see Appendix A for ICD-10 definitions). Both primary and secondary diagnosis were used to maximize baseline characteristics and to avoid missing possible endpoints. Characteristics at baseline data were collected and compared for bleeders and non-bleeders as well as for different age groups $(<60,60-80$ and $>80$ years $=$ elderly $)$ using non-parametric tests (Chi-square test was used for categorical data and Kruskal Wallis test for age between groups). Primary endpoint was major bleeding defined as bleeding leading to inpatient or specialized outpatient hospital care. Patients contributed with follow-up time for major bleeding until that endpoint occurred or until the end of 2017. Follow-up also ended in the event of death or if treatment stopped or changed in terms of dosage or substance. Major bleedings were subcategorized if ICD-coded as gastrointestinal or intracranial. Any bleeding that led to hospital care was termed as other bleeding. R Core Team (Version 2020; R Foundation for Statistical Computing, Vienna, Austria) was used for data analysis. Incidence rates were calculated for bleeding end-points (major bleeding, gastrointestinal bleeding, intracranial bleeding and other bleeding) in all patients and for the different age groups. Cumulative risk of bleeding end-points were presented with Kaplan Meier survival curves. Both univariate and multivariate Cox regression tests were used to screen possible risk or protective factors for major bleeding. 95\% confidence intervals were used.

\section{Results}

In total 18219 patients with NOAC-treated deep vein thrombosis (DVT) or pulmonary embolism (PE) were included in the study. The mean age was 69.3 years and $52.4 \%$ were males. Among included patients $38.8 \%$ had acute DVT, $9.1 \%$ had recurrent DVT, $40.5 \%$ had acute PE, 5.3\% recurrent PE and $6.3 \%$ DVT or PE not classified as acute or recurrent. The majority had a VTE for the first time (85.6\%). The overall 
Table 1 Characteristics for all patients and major bleeders at baseline

\begin{tabular}{|c|c|c|c|c|}
\hline & Total, $\mathrm{n}=18219 \mathrm{n}(\%)$ & Bleeders, $\mathrm{n}=938 \mathrm{n}(\%)$ & $\begin{array}{l}\text { Non-bleeders, } \\
\mathrm{n}=17281 \mathrm{n}(\%)\end{array}$ & $p$-value \\
\hline Age, median (IQR) & $69.4(56.8-78.5)$ & $74.2(65.1-82)$ & $69.1(56.4-78.3)$ & $<0.01$ \\
\hline Sex (male) & $9544(52.4)$ & $461(49.1)$ & $9083(52.6)$ & 0.045 \\
\hline First DVT/LE ${ }^{\mathrm{a}}$ & $15587(85.6)$ & $767(81.8)$ & $14820(85.8)$ & $<0.01$ \\
\hline Prior warfarin treatment & $5682(31.2)$ & $359(38.3)$ & $5323(30.8)$ & $<0.01$ \\
\hline Hypertension & $1606(8.8)$ & $120(12.8)$ & $1486(8.6)$ & $<0.01$ \\
\hline Myocardial infarction & $1119(6.1)$ & $78(8.3)$ & $1041(6)$ & $<0.01$ \\
\hline $\mathrm{PCI}^{\mathrm{b}}$ & $148(0.8)$ & $11(1.2)$ & $137(0.79)$ & 0.28 \\
\hline Atrial fibrillation & $1243(6.8)$ & $118(12.6)$ & $1125(6.5)$ & $<0.01$ \\
\hline Heart Failure & $892(4.9)$ & $79(8.4)$ & $813(4.7)$ & $<0.01$ \\
\hline TIA & $1532(8.4)$ & $57(6.1)$ & $510(3)$ & $<0.01$ \\
\hline Stroke & $1134(6.2)$ & $101(10.8)$ & $1033(6)$ & $<0.01$ \\
\hline Vascular disease & $1587(8.7)$ & $114(12.2)$ & $1473(8.5)$ & $<0.01$ \\
\hline Diabetes & $963(5.3)$ & $52(5.5)$ & $911(5.3)$ & 0.77 \\
\hline $\mathrm{COPD}^{\mathrm{c}}$ & $1491(8.2)$ & $112(11.9)$ & $1379(8)$ & $<0.01$ \\
\hline Dementia & $252(1.4)$ & $11(1.2)$ & $241(1.4)$ & 0.67 \\
\hline Anemia & $748(4.1)$ & $61(6.5)$ & $687(4)$ & $<0.01$ \\
\hline History of major bleeding & $3428(18.8)$ & $351(37.4)$ & $3077(17.8)$ & $<0.01$ \\
\hline Gastrointestinal & $888(4.9)$ & $112(11.9)$ & $776(4.5)$ & $<0.01$ \\
\hline Intracranial & $452(2.5)$ & $52(5.5)$ & $400(2.3)$ & $<0.01$ \\
\hline Previous other bleeding & $2416(13.3)$ & $235(25.1)$ & $2181(12.6)$ & $<0.01$ \\
\hline Renal failure & $343(1.9)$ & $28(3)$ & $315(1.8)$ & 0,02 \\
\hline Excessive alcohol use & $558(3.1)$ & $40(4.3)$ & $518(3)$ & 0.04 \\
\hline Fall & $4298(23.6)$ & $275(29.3)$ & $4023(23.3)$ & $<0.01$ \\
\hline Liver disease & $168(0.92)$ & $13(1.4)$ & $155(0.9)$ & 0.18 \\
\hline Cancer & $2145(11.8)$ & $149(15.9)$ & $1996(11.6)$ & $<0.01$ \\
\hline Cancer in GI-tract ${ }^{\mathrm{d}}$ & $387(2.1)$ & $27(2.9)$ & $360(2.1)$ & 0.13 \\
\hline
\end{tabular}

distribution of NOAC substances were rivaroxaban $54.8 \%$, apixaban $42.0 \%$, dabigatran $3.2 \%$ and edoxaban $0.1 \%$. Low dose NOAC (i.e. rivaroxaban $10 \mathrm{mg} \times 1$, apixaban $2.5 \mathrm{mg} \times 2$, dabigatran $110 \mathrm{mg} \times 2$ or edoxaban $30 \mathrm{mg} \times 1$ ) was used in $13.2 \%$ of the patients. The median follow-up time was 183 days (IQR 92-360). Characteristics at baseline when NOAC-treatment was started are presented for all patients in Table 1 (with separate columns for bleeders and non-bleeders) and Online Resource 1 (with separate columns for different age groups).

Among the 18,219 patients 938 had a major bleeding and the rate of major bleeding was 6.62 (95\% CI 6.19-7.06) per 100 treatment years. Intracranial bleeding was found in 81 patients, 293 patients had gastrointestinal and 590 patients other bleedings, with corresponding bleeding rates of 0.55 (CI 0.43-0.67), 2.00 (CI 1.77-2.24) and 4.11 (CI 3.77-4.45) respectively. Major bleeding rate for patients under 60 years was 3.40 (CI 2.84-3.97), between 60 and 80 years 6.85 (CI
6.23-7.47) and over 80 years 11.27 (CI 9.96-12.57) (Fig. 1). The cumulative risk of major bleeding was significantly increased with higher age (Fig. 2). A similar pattern was observed for gastrointestinal bleeding and other bleeding but the risk of intracranial bleeding was not significantly different between the age groups.

Results of univariate and multivariate Cox regression are presented in Fig. 3. Exact numbers are presented in Online Resource 2. Univariate Cox regression analysis indicate that female sex, hypertension, myocardial infarction, atrial fibrillation, heart failure, vascular disease, anemia, renal failure, fall tendency and cancer were associated with a higher risk of major bleeding but these risk factors were not confirmed in multivariate analysis. Statistically significant risk factors associated with major bleeding after multivariate Cox regression analysis were age (HR 1.38, CI 1.27-1.50), previous stroke (HR 1.28, $\mathrm{Cl} 1.03-1.58)$ or transient ischemic attack (TIA) (HR 1.33, Cl 1.01-1.76), COPD (HR 1.28, CI 1.04-1.60) and 

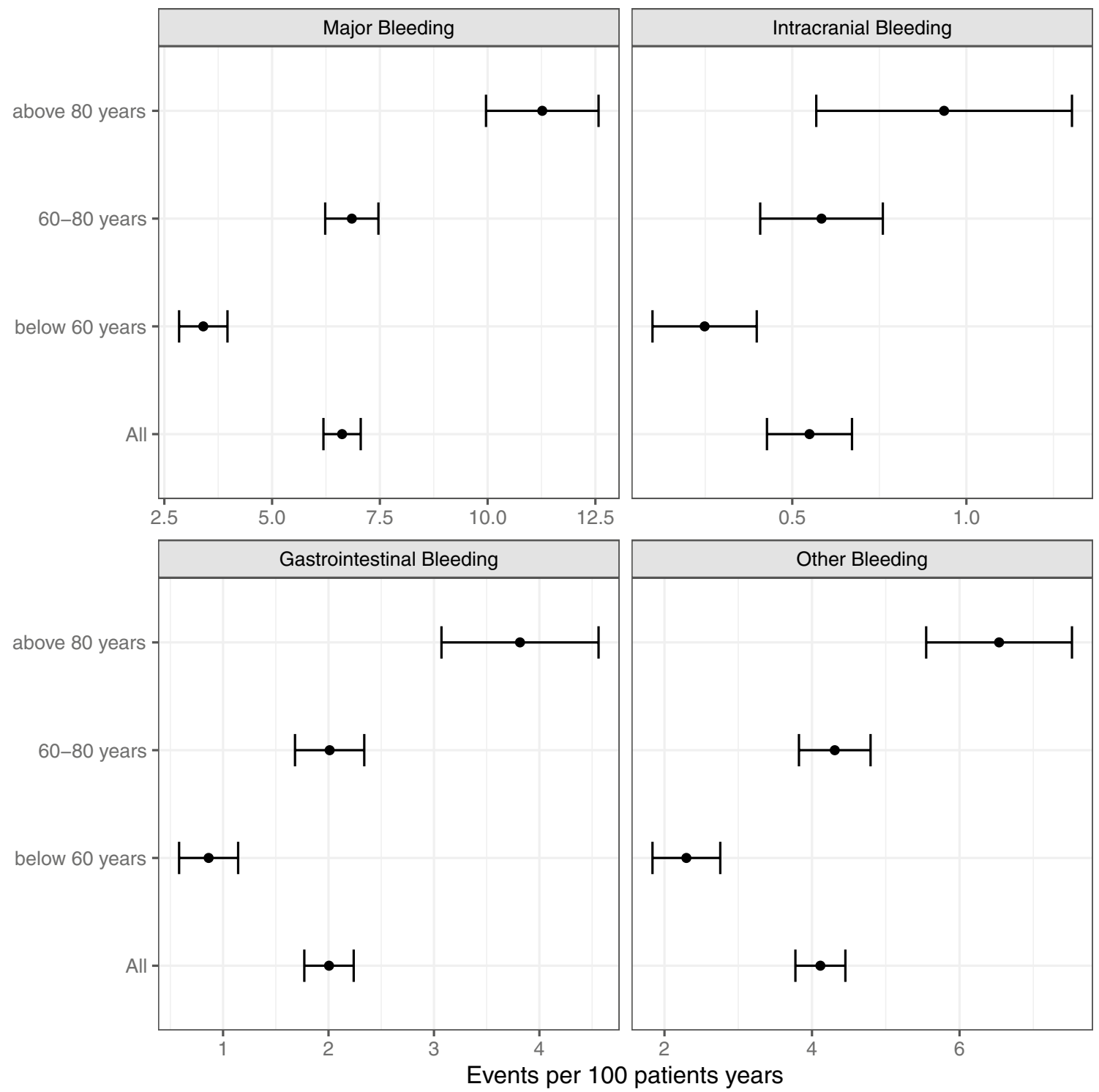

Fig. 1 Bleeding rates per 100 patient years for all patients and in different age groups ( $<60$ years, $60-80$ years and $>80$ years). Rates for major bleeding, gastrointestinal, intracranial and other bleeding are presented in separate boxes with means and $95 \%$ confidence intervals

earlier major bleeding (HR 1.58, Cl 1.09-2.30). Prior warfarin treatment was a protective factor (HR 0.67, CI 0.58-0.78).

\section{Discussion}

In this real-world cohort of patients with VTE on treatment with NOACs, the overall rate of major bleeding was 6.62 per 100 treatment years, with almost doubled bleeding rate [11, 11] among the elderly ( $>80$ years), driven by an increase in both gastrointestinal and other non-intracranial bleeds. Compared to the two major clinical trials EINSTEINVTE and AMPLIFY the major bleeding rate is about 5\% higher in absolute numbers $[16,17]$. This is probably due to differences in cohort characteristics, study design and definitions of events. A possible explanation for the overall high bleeding risk in our study could be a broader definition of major bleeding which here is dependent on the physicians' clinical diagnosis rather than strict criteria of hemoglobin drop or the need of blood transfusion. False positive bleeding rates is also likely when based on administrative ICDcodes without a complementary chart review $[18,19]$.

A similar study to this using administrative ICD-10 codes for estimating bleeding rates, but with real life data on warfarin with well-regulated TTR instead of NOACs in treatment for venous thromboembolism found a lower risk of major bleeding and reported a major bleeding rate of 2.36 per 100 treatment years [8]. This might be due to a slightly older 


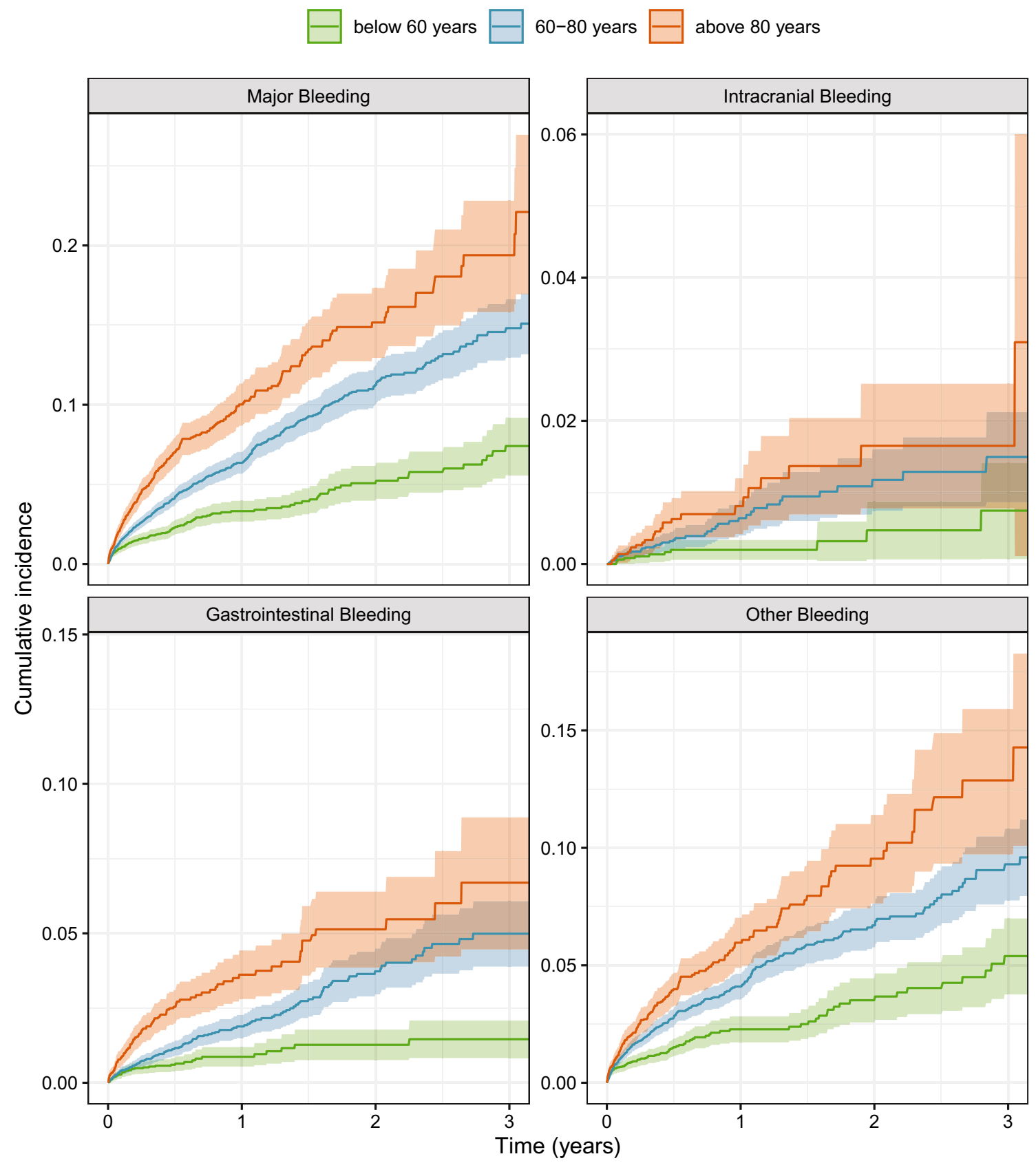

Fig. 2 Age stratified cumulative risk of major bleeding. Cumulative risk of bleeding (y-axis) depending on years from treatment start (x-axis) in different age groups (red: $>80$ years, blue: $60-80$ years

population in our study even though we in general report lower comorbidity. Our cohort might also be more prone to bleeding since the proportion of previous major bleeding was considerably higher ( $18.8 \%$ compared to $7.1 \%$ ). Historic major bleeding has been identified as an important risk factor for major bleeding in other studies $[8,9,20]$. Most of our patients also had a venous thrombosis for the first time (85.6\% compared to $44.3 \%$ ) and had therefore probably to a lesser extent been exposed to anticoagulation before. Both and green: $<60$ years). Separate boxes for major bleeding, gastrointestinal bleeding, intracranial bleeding and other bleeding

studies report a protective effect of prior warfarin treatment and this might add to the explanation of the higher bleeding rate in this study. Furthermore, rivaroxaban together with apixaban dominated this study and recent observation studies on oral anticoagulation in atrial fibrillation reports that rivaroxaban is not protective regarding major bleeding [21] and might even be harmful compared to warfarin [22].

Cox regression analysis revealed age, previous stroke or TIA, COPD and historic major bleeding as independent risk 


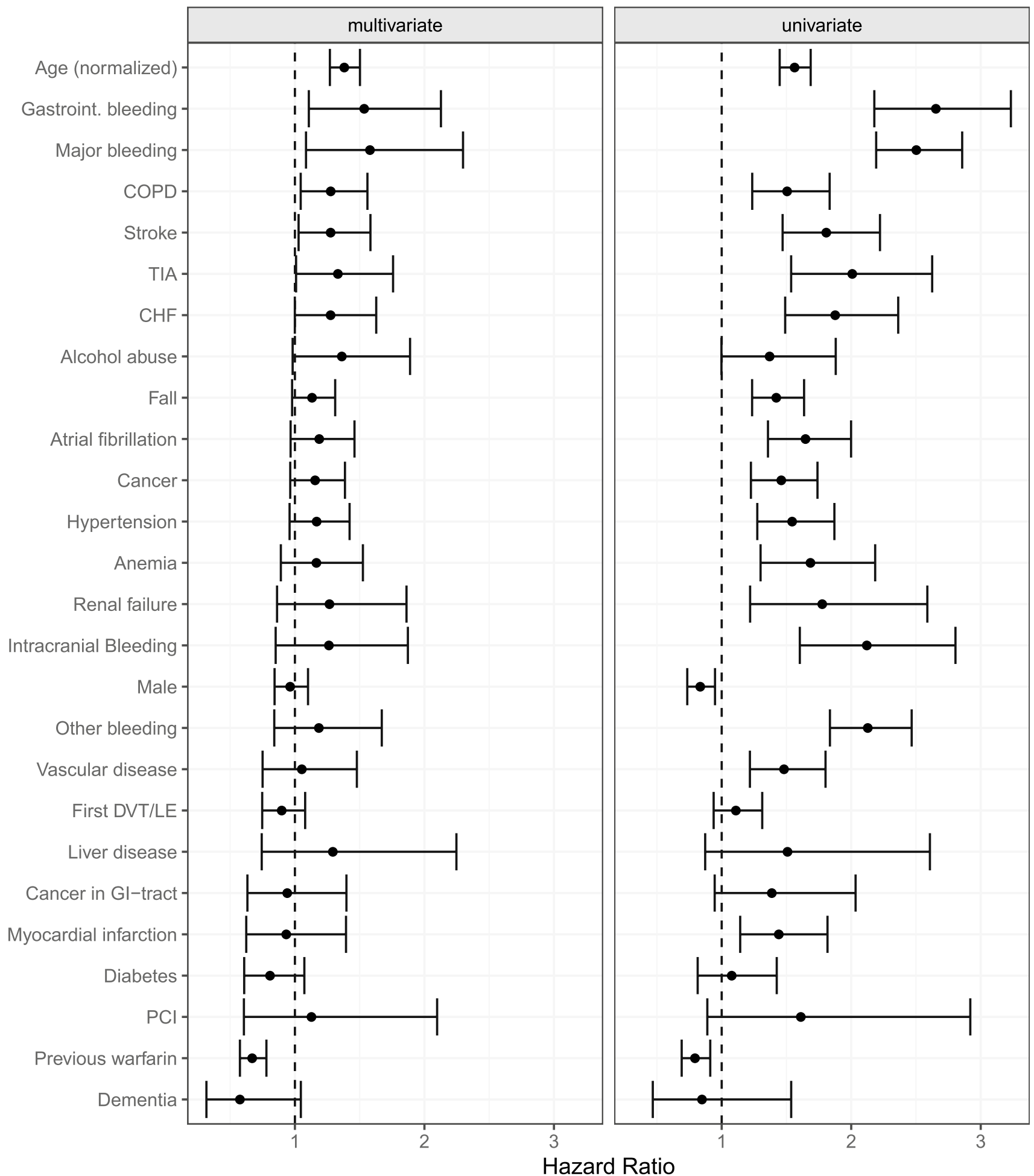

Fig. 3 Univariate and multivariate Cox regression analysis with major bleeding endpoint. Hazard ratios for different variables with $95 \%$ confidence intervals. Numbers are presented in Online Resource 2

factors associated with major bleeding. Prior warfarin treatment was a protective factor which probably reflect the fact that these patients are a selected group that tolerates anticoagulation well and therefore are less prone to bleed. These findings differentiate slightly from the results of a prospective study in patients with anticoagulation as stroke prophylaxis due to atrial fibrillation [9], but since that study was not a pure study on NOACs the comparability is obscured. 
Identified risk factors there which were not confirmed in our study were vascular disease, abnormal renal function, abnormal liver function and excessive alcohol use. However, findings of age and history of major bleeding as risk factors were the same. Our results are also to some extent different from the similar observation study on warfarin treatment due to VTE [8]. There, atrial fibrillation actually was a protective factor and hypertension, cardiac failure, alcohol abuse and anemia were identified as risk factors. This was not found in our study with patients on NOACs due to VTE. However, the common findings of age, COPD and history of major bleeding strengthens the reliability of our results. Some questions still remain. How is it that COPD increases the bleeding risk? If the increased risk of bleeding in patients with previous stroke or TIA is explained by concurrent antiplatelet therapies why is it not the same in myocardial infarction? Possibly, COPD or previous stroke could be markers for more frail patients, which could account for some of the increased bleeding risk.

\section{Conclusion}

A high rate of major bleeding causing in-hospital care was found especially in the elderly and in patients with previous stroke or TIA, COPD or history of major bleeding. In these patient groups, the risk of major bleeding should be of concern for the physician deciding on dose and treatment duration of NOACs as secondary prophylaxis for VTE. Extended anticoagulation with low dose NOAC in clinical equipoise situations is supported by two RCTs [23, 24]. In the oldest patients, a reduced NOAC dose could be considered more often due to their higher bleeding rate, although further studies are needed to determinate the efficacy of low dose NOACs in acute VTE in the elderly.

\section{Limitations}

This is a retrospective register-based study with all limitations that comes with it and bias cannot be ruled out. Data depends on physicians subjective diagnostic approach and the validity for bleeding end-points based on ICD-codes are questionable. Prevalence of underlying parameters such as hypertension and alcohol abuse could be underestimated since information from the primary health care is lacking in the NPR. The possibility of interactions effects such as concurrent antiplatelet also remains undetectable.

Funding Open access funding provided by Umea University. This work was supported by The Swedish Heart-Lung Foundation, grant number 20150435, https://www3.hjart-lungfonden.se/ViewPublic Report.aspx(AS).

Data availability Raw data are not attached.

Code availability R Core Team (Version 2020; R Foundation for Statistical Computing, Vienna, Austria) was used for data analysis.

\section{Compliance with ethical standards}

Conflict of interest N.W and H.R declare that they have no conflict of interest. A.S was the principal investigator of the RE-VERSE AD study in Sweden and has received consultancy or lecture fees from Bayer, Boehringer-Ingelheim, Bristol-Myers Squibb, Merck Sharp and Dohme, Takeda Pharma and Pfizer.

Ethics approval This study was performed in line with the principles of the Declaration of Helsinki. Approval was granted by the Ethics Committee of University. Dnr 2015/145-31.

Informed consent Article was accepted for publication by all authors.

Open Access This article is licensed under a Creative Commons Attribution 4.0 International License, which permits use, sharing, adaptation, distribution and reproduction in any medium or format, as long as you give appropriate credit to the original author(s) and the source, provide a link to the Creative Commons licence, and indicate if changes were made. The images or other third party material in this article are included in the article's Creative Commons licence, unless indicated otherwise in a credit line to the material. If material is not included in the article's Creative Commons licence and your intended use is not permitted by statutory regulation or exceeds the permitted use, you will need to obtain permission directly from the copyright holder. To view a copy of this licence, visit http://creativecommons.org/licenses/by/4.0/.

\section{Appendix}

\section{Appendix A: ICD-10 codes}

\begin{tabular}{ll}
\hline Venous thromboembolism & I26, I636, I676, I80-82 \\
\hline Hypertension & I10-15 \\
$\begin{array}{l}\text { Myocardial infarction } \\
\text { Percutanous coronary interven- } \\
\text { tion (PCI) }\end{array}$ & FNG-22, I24, I252 \\
Atrial fibrillation & I48 FNG05, Z955 \\
Heart Failure & I50, I110, I130, I132 \\
Valve malfunction & I05-08, I34-36, I39, Q22-24, T82 \\
Stroke & I63-64, I69 \\
TIA & G450-453, G458, G459 \\
Vascular disease & I21-22, I252, I70-71 \\
Diabetes & E10-14 \\
\hline
\end{tabular}




\begin{tabular}{|c|c|}
\hline Venous thromboembolism & I26, I636, I676, I80-82 \\
\hline $\begin{array}{l}\text { Chronic obstructive pulmonary } \\
\text { disease }\end{array}$ & $\mathrm{J} 40-70$ \\
\hline Dementia & F00-03 \\
\hline Anemia & $\begin{array}{l}\text { D50, D510, D513, D518, D519, } \\
\text { D52, D53, D55, D560-D562, } \\
\text { D568-D572, D588, D589, } \\
\text { D59-64 }\end{array}$ \\
\hline Major bleeding & $\begin{array}{l}\text { I60-I62, S064-066, R04, K250, } \\
\text { K252, K254, K256, K260, } \\
\text { K262, K2264, K266, K270, } \\
\text { K272, K274, K276, K280, } \\
\text { K282, K282, K286, K920-922, } \\
\text { K290, I850, I983, K625, D629, } \\
\text { R589 }\end{array}$ \\
\hline Gastrointesinal bleeding & $\begin{array}{c}\text { I850, I983, K250, K252, K254, } \\
\text { K256, K260, K262, K264, } \\
\text { K266, K270, K272, K274, } \\
\text { K276, K280, K282, K284, } \\
\text { K286, K625, K920-922 }\end{array}$ \\
\hline Intracranial bleeding & I60-I62, S064-066 \\
\hline Other bleeding & $\begin{array}{l}\text { D500, D508-509, D629, H356, } \\
\text { H922, N02, N938-939, R04, } \\
\text { R310 }\end{array}$ \\
\hline Renal failure & $\begin{array}{l}\text { I120, I131-132. N17-19, DR016, } \\
\text { DR024, KAS00, KAS10, } \\
\text { KAS20 }\end{array}$ \\
\hline Excessive alcohol use & $\begin{array}{l}\text { F10, K70, T51, Y90, Y91, E244, } \\
\text { G312, G621, G721, I426, K292, } \\
\text { K860, O354, Z714 }\end{array}$ \\
\hline Fall(s) & W00-19 \\
\hline Liver disease & K70-77, JJC, JJB \\
\hline Cancer & $\mathrm{C} 1-\mathrm{C} 9$ \\
\hline Cancer in GI-tract & $\mathrm{C} 15-\mathrm{C} 26$ \\
\hline Intracerebral bleeding & I60-I62, S064-066 \\
\hline
\end{tabular}

\section{References}

1. Naess IA, Christiansen SC, Romundstad P, Cannegieter SC, Rosendaal FR, Hammerstrøm J (2007) Incidence and mortality of venous thrombosis: a population-based study. J Thromb Haemost 5(4):692-699

2. Silverstein MD, Heit JA, Mohr DN, Petterson TM, O'Fallon WM, Melton LJ 3rd (1998) Trends in the incidence of deep vein thrombosis and pulmonary embolism: a 25-year population-based study. Arch Intern Med 158(6):585-593

3. Goldhaber SZ, Bounameaux H (2012) Pulmonary embolism and deep vein thrombosis. Lancet 379(9828):1835-1846

4. Barritt DW, Jordan SC (1960) Anticoagulant drugs in the treatment of pulmonary embolism. A controlled trial. Lancet 1(7138):1309-1312

5. Carrier M, Le Gal G, Wells PS, Rodger MA (2010) Systematic review: case-fatality rates of recurrent venous thromboembolism and major bleeding events among patients treated for venous thromboembolism. Ann Intern Med 152(9):578-589

6. Kearon C, Akl EA, Comerota AJ, Prandoni P, Bounameaux H, Goldhaber SZ et al (2012) Antithrombotic therapy for VTE disease: antithrombotic therapy and prevention of thrombosis, 9th ed: American College of Chest Physicians Evidence-Based Clinical Practice Guidelines. Chest 141(2 Suppl):e419S - e496

7. van der Hulle T, Kooiman J, den Exter PL, Dekkers OM, Klok FA, Huisman MV (2014) Effectiveness and safety of novel oral anticoagulants as compared with vitamin $\mathrm{K}$ antagonists in the treatment of acute symptomatic venous thromboembolism: a systematic review and meta-analysis. J Thromb Haemost 12(3):320-328

8. Sanden P, Renlund H, Svensson PJ, Sjalander A (2016) Bleeding complications in venous thrombosis patients on well-managed warfarin. J Thromb Thrombolysis 41(2):351-358

9. Rohla M, Weiss TW, Pecen L, Patti G, Siller-Matula JM, Schnabel RB et al (2019) Risk factors for thromboembolic and bleeding events in anticoagulated patients with atrial fibrillation: the prospective, multicentre observational PREvention oF thromboembolic events-European Registry in Atrial Fibrillation (PREFER in AF). BMJ Open 9(3):e022478

10. Chang SH, Chou IJ, Yeh YH, Chiou MJ, Wen MS, Kuo CT et al (2017) Association between use of non-vitamin k oral anticoagulants with and without concurrent medications and risk of major bleeding in nonvalvular atrial fibrillation. JAMA 318(13):1250-1259

11. Monelli M, Molteni M, Cassetti G, Bagnara L, De Grazia V, Zingale L et al (2019) Non-vitamin K oral anticoagulant use in the elderly: a prospective real-world study - data from the REGIstry of patients on non-vitamin K oral Anticoagulants (REGINA). Vasc Health Risk Manag 15:19-25

12. Staerk L, Sherer JA, Ko D, Benjamin EJ, Helm RH (2017) Atrial fibrillation: epidemiology, pathophysiology, and clinical outcomes. Circ Res 120(9):1501-1517

13. Hald EM, Enga KF, Løchen M-L, Mathiesen EB, Njølstad I, Wilsgaard $\mathrm{T}$ et al (2014) Venous thromboembolism increases the risk of atrial fibrillation: the Tromso study. J Am Heart Assoc 3(1):e000483

14. Juhlin T. Auricula. Yearly report 2017

15. Socialstyrelsen. Information för Patientregistret, registerår 2018, version 1. 2019-08-23

16. Bauersachs R, Berkowitz SD, Brenner B, Buller HR, Decousus H, Gallus AS et al (2010) Oral rivaroxaban for symptomatic venous thromboembolism. N Engl J Med 363(26):2499-2510

17. Agnelli G, Buller HR, Cohen A, Curto M, Gallus AS, Johnson $M$ et al (2013a) Oral apixaban for the treatment of acute venous thromboembolism. N Engl J Med 369(9):799-808

18. Joos C, Lawrence K, Jones AE, Johnson SA, Witt DM (2019) Accuracy of ICD-10 codes for identifying hospitalizations for acute anticoagulation therapy-related bleeding events. Thromb Res 181:71-76

19. Delate T, Jones AE, Clark NP, Witt DM (2017) Assessment of the coding accuracy of warfarin-related bleeding events. Thromb Res 159:86-90

20. Alikhan R, Lefevre C, Menown I, Lister S, Bird A, You M et al (2019) Risk of recurrent bleeding events in nonvalvular atrial fibrillation treated with vitamin $\mathrm{K}$ antagonists: a clinical practice research datalink study. TH Open 3(4):e316-e324

21. Sjalander S, Sjogren V, Renlund H, Norrving B, Sjalander A (2018) Dabigatran, rivaroxaban and apixaban vs. high TTR warfarin in atrial fibrillation. Thromb Res 167:113-8

22. Lip GYH, Keshishian A, Li X, Hamilton M, Masseria C, Gupta K et al (2018) Effectiveness and safety of oral anticoagulants among nonvalvular atrial fibrillation patients. Stroke 49(12):2933-2944

23. Weitz JI, Lensing AWA, Prins MH, Bauersachs R, Beyer-Westendorf J, Bounameaux $\mathrm{H}$ et al (2017) Rivaroxaban or aspirin for extended treatment of venous thromboembolism. N Engl J Med 376(13):1211-1222 
24. Agnelli G, Buller HR, Cohen A, Curto M, Gallus AS, Johnson M et al (2013b) Apixaban for extended treatment of venous thromboembolism. N Engl J Med 368(8):699-708
Publisher's Note Springer Nature remains neutral with regard to jurisdictional claims in published maps and institutional affiliations. 